\title{
Validation of the spiritual and religious attitudes in dealing with illness (SpREUK) in Portuguese Alzheimer's patients
}

\section{G. Pereira, M. Vilaça, S. Pedras, S. Vieira \& S. Lima}

To cite this article: M. G. Pereira, M. Vilaça, S. Pedras, S. Vieira \& S. Lima (2020)

Validation of the spiritual and religious attitudes in dealing with illness (SpREUK) in

Portuguese Alzheimer's patients, Journal of Religion, Spirituality \& Aging, 32:2, 172-187, DOI:

$10.1080 / 15528030.2019 .1610989$

To link to this article: https://doi.org/10.1080/15528030.2019.1610989

\section{Published online: 09 May 2019.}

\section{Submit your article to this journal $\sqsubset$}

山 Article views: 110

a

View related articles

View Crossmark data $־$

Citing articles: 2 View citing articles 


\title{
Validation of the spiritual and religious attitudes in dealing with illness (SpREUK) in Portuguese Alzheimer's patients
}

\author{
M. G. Pereira (10 ${ }^{a}$, M. Vilaçaa , S. Pedras (10 ${ }^{a}$, S. Vieiraa, and S. Lima ${ }^{b}$ \\ anniversirty of Minho, Braga, Portugal; ${ }^{b}$ CESPU, Institute of Research and Advanced Training in Health \\ Technologies Resarch Centre, Gandra, Portugal
}

\begin{abstract}
Literature shows that spirituality is a helpful resource for patients to cope with illness, having a positive impact on their quality of life. This study aimed to analyze the psychometric qualities of the Spiritual and Religious Attitudes in Dealing with Illness (SpREUK) using a sample of 128 Portuguese Alzheimer's patients. Results showed that the instrument kept its original factorial structure, with a good adjustment and reliability in all subscales, and associations with quality of life and mindfulness. Therefore, the Portuguese version of the SpREUK has appropriate psychometric properties and is an important resource to assess spirituality in Alzheimer's patients.
\end{abstract}

\section{KEYWORDS}

Spirituality; SpREUK;

Alzheimer disease;

mindfulness; quality of life

\section{Introduction}

Dementia is a disease characterized by cognitive and functional decline, including memory impairment and cognitive disorders, apraxia, agnosia, and disruption of executive functioning (American Psychiatric Association, 2013). Within this group of pathologies, several types of dementias are found with common symptoms and, therefore, difficult to differentiate, the most common being vascular dementia and Alzheimer's disease (AD).

In 2009, the World Report on Alzheimer's, conducted by the Alzheimer's Disease International in which they used 135 publications describing 147 studies, estimated that in 2010 about 35.6 million people worldwide would live with dementia, with the gross estimate for Western Europe of 7.2\%. The World Alzheimer's Report (Alzheimer's Disease International, 2015) says that 46.8 million people have dementia, $12-13 \%$ higher than the estimate in the 2009 report, with an increase in new cases in Asia, America and Africa, while in Europe is slightly decreasing, this value being associated with the average age in these same continents. Alzheimer Portugal (2013) estimates that there are about 153,000 people with dementia, 90,000 with 
Alzheimer's. AD is characterized, in cerebral terms, by a deficit in the cholinergic transmission and the formation of senile plaques containing betaamyloid protein (Orhan, Orhan, Subutay-Oztekin, Ak, \& Sener, 2009). The tangles in the essential structures of neurons that can be detected by highdefinition imaging tests are one of the main biomarkers that allow the probability of the diagnosis, together with the clinical symptomatology (Dourado, Laks, Leibing, \& Engelhardt, 2006). AD is characterized by the development of multiple cognitive deficits expressed in one or several cognitive domains, resulting in a continuous and gradual cognitive decline, especially in the memory and learning functions, being excluded other etiologies of vascular, neurodegenerative, neurological or mental origin.

In addition to the functional and cognitive deficits resulting from the disease, the literature shows that patients with AD present depressed mood, high levels of anxiety and irritability, as well as a reduction in the quality of interpersonal relationships, which is reflected on quality of life (Black et al., 2012; Conde-Sala, Garre-Olmo, Turró-Garriga, López-Souza, \& VilaltaFranch, 2009; Woods et al., 2014). Therefore, it is important to help patients to mobilize strategies to deal with the losses associated with $\mathrm{AD}$, as well as to understand them.

Spirituality is a resource that can help patients to cope with illness and, consequently, has a positive impact on their quality of life (Büssing, 2010; Katsuno, 2003). Studies on AD indicate that patients preserve their spirituality, remaining connected, regardless of manifest cognitive impairments (Dalby, Spelinger \& Boddington, 2011). According to Sullivan and Beard (2014), spirituality allows patients with AD to feel more comfortable with themselves, to be hopeful, to receive help regarding memory losses, to find tranquility and to reduce isolation, which is reflected in a decrease in medication and in maintaining the identity and preservation of the Self. Thus, spirituality is associated with better coping with the disease (Ali et al., 2015; Chen, Lin, Chuang, \& Chen, 2017; McGee, Carlson, \& Myers, 2013) and quality of life (Katsuno, 2003).

Spirituality is associated with better outcomes regarding physical health, psychological wellbeing and social relationships (Counted, Possamai, \& Meade, 2018). The literature has shown that spirituality predicted quality of life in patients with chronic disease (Adegbola, 2011) acting as a coping strategy (Clayton-Jones \& Haglund, 2016). Spirituality may provide meaning in life (Davison \& Jhangri, 2013) that promotes the psychological adjustment to the illness.

In the literature, the importance of spirituality and mindfulness on psychological distress is consensual. According to Carmody, Reed, Kriesteller and Merriam (2008), the development of spirituality and mindfulness allows patients to find meaning and peace of mind regarding the illness reducing the psychological distress and somatic symptoms associated. In addition, the 
experience of spirituality and mindfulness' practices was associated with a reduction in depressive symptoms (Greeson et al., 2015).

Considering the relevance of spirituality to health in general, as well as its full potential in treatment of chronic illness (Powell, Shahabi, \& Thoresen, 2003; Seeman, Dubin, \& Seemann, 2003; Sloan \& Bagiella, 2002), it becomes essential to make spirituality assessment measures available in health care settings. Regarding the existing spirituality evaluation measures, the Spiritual and Religious Attitudes in Dealing with Illness (SpREUK; Büssing, 2010; Büssing, Ostermann, \& Matthiessen, 2005) is a relevant instrument designed to evaluate the chronic patient's perceptions of the impact of spirituality on health and how to deal with the disease. Currently, there are different versions of SpREUK as a result of its initial version's optimization process the 25-item version (SpREUK 1.1), the 18-item version (SpREUK 1.2), the 16-item version (SpREUK 1.2b), the 15-item version (SpREUK-15), the 10item version (SpREUK-SF10), already tested in the German context with secular patients (Büssing, 2010; Büssing, Osterman, \& Koenig, 2007; Büssing et al., 2005), Arabic Muslims (Büssing, Abu-Hassan, Matthiessen, \& Osterman, 2007), Orthodox Jews (Zini, Büssing, \& Sgan-Cohen, 2010) and, more recently, in the Polish context with predominantly catholic clinical population (Büssing, Franczak, Surzykiewick, 2016). The most widely used version is the short version of 15 items that evaluates three independent dimensions: (i) Search for support/access to spirituality, (ii) Trust in higher guidance/source and (iii) Reflection and positive interpretation of disease. Therefore, the aim of the present study was to analyze the psychometric qualities of the adapted Portuguese version of SpREUK-15 in Portuguese Alzheimer patients.

\section{Method}

\section{Participants and procedure}

Patients were recruited from four Hospitals in the North of Portugal. The inclusion criteria were: probable $\mathrm{AD}$ according to the Diagnostic and Statistical Manual of Mental Disorders-IV (DSM-IV) and the National Institute of Neurological and Communicative Disorders and Stroke/ Alzheimer's Disease and Related Disorders Association (NINCDS/ ADRDA) criteria. Patients were identified as having a mild AD if they scored 1 in the Clinical Dementia Rating scale. Neuropsychological screening scales, the Mini Mental State Examination (MMSE) and the Montreal Cognitive Assessment (MoCA) were also included in patient's assessment in addition to the clinical criteria of the international guidelines used by physicians for the diagnosis of initial $\mathrm{AD}$, in order to evaluate the patients' autonomy and critical capacity to respond to the 
evaluation protocol. In fact, since the early-stage AD is characterized by memory changes (e.g., forgetting names, phone numbers), mild AD symptoms may go unnoticed and are often underestimated by the patient, family, and friends, who attribute those changes to the natural aging process, with a small impact on the patient's overall functioning. Exclusion criteria included having a severe psychiatric disorder (e.g., psychosis) or a cerebral vascular disease. If patients fulfilled the inclusion criteria, they were invited by the neurologist to participate in the study. All patients signed an informed consent form and participation was voluntary.

\section{Measures}

Spiritual and Religious Attitudes in Dealing with Illness (SpREUK; Büssing, 2010; Büssing et al., 2005) scale is a self-report measure designed to assess patients with chronic diseases' attitudes and convictions towards spirituality/religiosity. SpREUK contains a total of 15 items distributed through three subscales: i) Search (for support/access), ii) Trust (in higher guidance/source) and iii) Reflection (positive interpretation of the disease). All items are scored on a 5-point Likert scale from disagreement to agreement $(0=$ "does not apply at all", $1=$ "does not truly apply", $2=$ "don't know", 3 = "applies quite a bit" and $4=$ "applies very much") and a higher score indicates a greater use of spirituality to deal with the chronic disease. In the original version, the 15-item version showed a Cronbach alpha of 0.94.

Quality of Life-Alzheimer's Disease (QOL-AD; Logsdon, Gibbons, McCurry, \& Teri, 2002) questionnaire assesses the QoL specifications for patients with Alzheimer's dementia. The scale consists of 13 items, scored in a Likert scale of 1 ("poor") to 4 ("excellent"), divided in the following dimensions: Physical health, Energy, Humor, Living conditions, Memory, Family, Marriage, Home ownership, Ability to do domestic tasks, Engaging in activities that provide pleasure, Money and general life. The results of the total scale range from 13 to 52 and higher scores indicate better QoL. The Portuguese adapted version (Bárrios et al., 2013) found a Cronbach alpha of .87. This study used the QOL-AD global score and the Cronbach alpha was 0.88 .

Cognitive and Affective Mindfulness Scale-Revised (CAMSR; Feldman, Hayes, Kumar, Greeson, \& Laurenceau, 2007) is a 12-item questionnaire that assesses the regulation of attention, orientation to the experience of the present without judgments and conditioned response patterns. Items are scored on a 4-point Likert scale, from 1 ("not at all") to 4 ("almost always") and higher score reflect greater use of strategy and quality of mindfulness. The Portuguese adaptation in AD patients (Pereira, 
Rego, \& Lima, 2015) includes 9 items. The Cronbach for the total scale was 0.83 , in this study.

\section{Data analysis}

After conducting descriptive analyses, exploratory factor analyses (EFA) and confirmatory factor analyses (CFA) were performed. Maximum likelihood estimation was used for confirmatory structural model assessment. To evaluate the models' fit, the following commonly used indices were considered: ratio of chi-square over the number of degrees of freedom $\left(\chi^{2} / d f\right)$, TuckerLewis index (TLI), comparative fit index (CFI), standardized root mean residual (SRMR) and root-mean-square error of approximation (RMSEA). The suggested reference values for $\chi^{2} / d f$ are values under 2 (Ullman, 2001); for CFI and TLI values equal or greater than .95 (Hu \& Bentler, 1995); and for SRMR and RMSEA values below .08 (Hair, Anderson, Tatham, \& Black, 1995). Reliability was performed through Cronbach's alpha coefficients, while external validity evidence was tested using Pearson's correlation analysis. All statistical analyses were performed using SPSSS and AMOS software (version 25).

\section{Results}

\section{Sample characteristics}

The sample consisted of 128 patients with Alzheimer's disease, 44 males and 84 females, aged between 56 and 88 years, with a mean of 76.05 years $(\mathrm{SD}=$ 6.92); $63.3 \%$ were married/living together, $31.3 \%$ were widowers, $4.7 \%$ were single and $0.8 \%$ were divorced. Of the total sample, $41.4 \%$ lived with the spouse/partner, $39.8 \%$ within the nuclear family, and $9.4 \%$ alone, $4.7 \%$ were in an institution/nursing home, $3.9 \%$ lived with the extended family and $0.8 \%$ lived alone with institutional support. Participants were mainly Catholics (96.1\%) with the remaining being Evangelicals (2.3\%), Jehovah Witnesses $(0.8 \%)$ or agnostic $(0.8 \%)$ (Table 1$)$.

\section{Factor analysis}

The results of Bartlett's sphericity and the Kaiser-Meyer-Olkin (KMO) tests confirmed the sample adequacy to proceed with factor analysis $\left(\chi^{2}=1558.17\right.$, $p<.001 ; \mathrm{KMO}=0.934)$. An initial EFA revealed two factors that together explained $68.15 \%$ of the total variance. Subsequently, a rotated bi-factorial solution using Varimax rotation was conducted in order to clarify the items allocation by both factors, explaining $53.67 \%$ of the total variance and aggregating all items from the original Search and Trust scales in one factor 
Table 1. Sample's sociodemographic characterization ( $N=128)$.

\begin{tabular}{|c|c|c|c|c|}
\hline & Min & Max & Mean & SD \\
\hline \multirow[t]{2}{*}{ Age } & 56 & 88 & 76.05 & 6.92 \\
\hline & & & & $\%(n)$ \\
\hline \multicolumn{5}{|l|}{ Gender } \\
\hline Men & & & & $34.4(44)$ \\
\hline Women & & & & $65.6(84)$ \\
\hline \multicolumn{5}{|l|}{ Marital status } \\
\hline Single & & & & $4.7(6)$ \\
\hline Married/Non-married partnership & & & & $63.3(81)$ \\
\hline Widowed & & & & $31.3(40)$ \\
\hline Divorced & & & & $0.8(1)$ \\
\hline \multicolumn{5}{|l|}{ Education } \\
\hline No education & & & & $19.5(25)$ \\
\hline$\leq$ Basic education & & & & $70.3(90)$ \\
\hline$\leq$ Secondary education & & & & $10.2(13)$ \\
\hline \multicolumn{5}{|l|}{ Household } \\
\hline Partner & & & & $41.4(53)$ \\
\hline Nuclear family & & & & $39.8(51)$ \\
\hline Living alone & & & & $9.4(12)$ \\
\hline Living alone with institutional support & & & & $0.8(1)$ \\
\hline Institution/nursing home & & & & $4.7(6)$ \\
\hline Extended family & & & & $3.9(5)$ \\
\hline \multicolumn{5}{|l|}{ Religion } \\
\hline Catholics & & & & $96.1(123)$ \\
\hline Evangelic & & & & $2.3(3)$ \\
\hline Jehovah witnesses & & & & $0.8(1)$ \\
\hline Agnostic & & & & $0.8(1)$ \\
\hline
\end{tabular}

(items $1,2,3,4,5,6,7,8,9,10$ ), while the remaining items were grouped in another factor (items 11, 12,13,14,15) corresponding to the Reflection scale. However, the bi-factor structure proposed by the EFA was not confirmed with the CFA, achieving inadequate goodness-of-fit indexes $\left(\chi^{2} / d f=2.176\right.$;

Table 2. Results of the CFA for the SpREUK Portuguese version.

\begin{tabular}{lccc}
\hline Version & & Domain & Statistical fit indices \\
\hline Original/ & Search: & $1 ; 2 ; 3 ; 4 ; 5$ & \\
German & Trust: & $6 ; 7 ; 8 ; 9 ; 10$ & \\
(Büssing, 2010) & Reflection: & $11 ; 12 ; 13 ; 14 ; 15$ & \\
Polish (Büssing et al., 2016) & Total: & $1-15$ & \\
& Search: & $1 ; 4 ; 5$ & $X^{2}(32)=42.95$ \\
& Trust: & $6 ; 8 ; 9 ; 10$ & $p=.094$ \\
& Reflection: & $13 ; 14 ; 15$ & $X^{2} / d f=1.34$ \\
& Total: & $1-10$ & CFI $=0.96$ \\
& & & RMSEA $=0.035$ \\
Initial Portuguese Model & Search: & $1 ; 2 ; 3 ; 4 ; 5$ & $X^{2} / d f=2.211$ \\
& Trust: & $6 ; 7 ; 8 ; 9 ; 10$ & CFI $=0.931$ \\
& Reflection: & $11 ; 12 ; 13 ; 14 ; 15$ & TLI $=0.917$ \\
& Total: & $1-15$ & SRMR $=0.054$ \\
& & & RMSEA $=0.098$ \\
Re-specified Portuguese Model & Search: & $1 ; 2 ; 3 ; 4 ; 5$ & $X^{2} / d f=1.714$ \\
& Trust: & $6 ; 7 ; 8 ; 9 ; 10$ & CFI $=0.960$ \\
& Reflection: & $11 ; 12 ; 13 ; 14 ; 15$ & TLI $=0.951$ \\
& Total: & $1-15$ & SRMR $=0.047$ \\
& & & RMSEA $=0.075$ \\
\hline
\end{tabular}




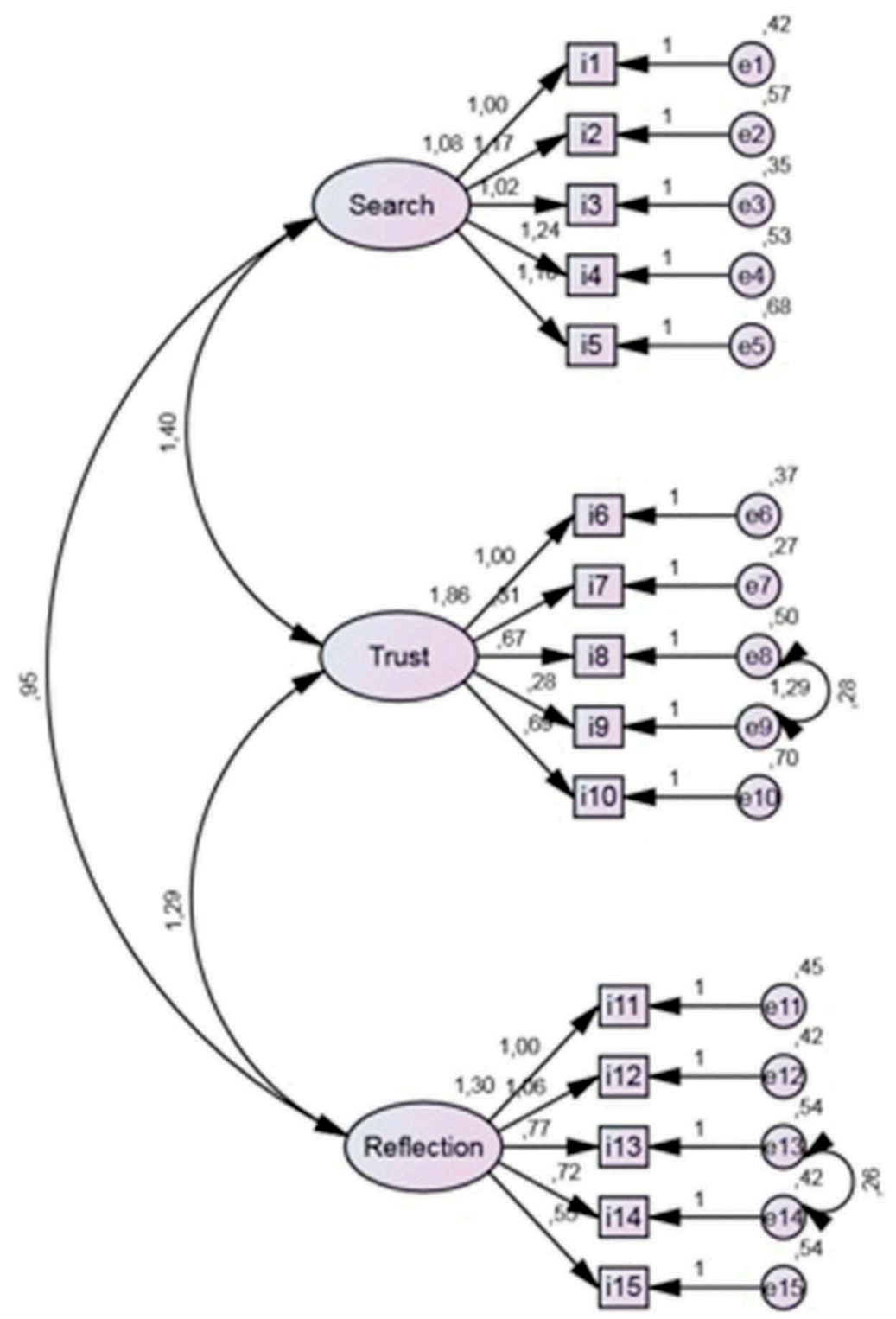

Figure 1. SpREUK re-specified model.

CFI $=0.932 ;$ TLI $=0.919 ;$ SRMR $=0.053 ;$ RMSEA $=0.096)$. Finally, the original structure was tested, obtaining a good fit for the tri-factorial solution $\left(\chi^{2} / D F=1.714 ; \mathrm{CFI}=0.960 ; \mathrm{TLI}=0.951 ;\right.$ SRMR $\left.=0.474 ; \mathrm{RMSEA}=0.075\right)$ (Table 2).

Figure 1 presents the final model with two correlations between errors, as suggested by the modification indices, specifically between items 8 ("I have faith in the spiritual guidance in my life") and 9 ("I am convinced that dead is not an end") and items 13 ("Something that happens to me is a hint that 
I should change my life") and 14 ("My illness is a change for my own development"). Both correlations were assumed since (i) they were low, (ii) the items had a shared component (purpose in life in the first case, and the importance of a life event in life changes, in the second), and (iii) the addition of correlated errors did not change the remaining parameter estimates as the model globally already had a reasonable fit and, therefore, the correlations are not necessarily related to sampling error (Hermida, 2015).

\section{Reliability analysis}

Internal consistency coefficients for Search, Trust and Reflection subscales and the total scale were $0.93,0.89$ and 0.90 and 0.95 , respectively (Table 3). Regarding the items frequency distribution and item difficulty, Search (DIF = $0.43)$, Trust $(\mathrm{DIF}=0.51)$ and Reflection $(\mathrm{DIF}=0.28)$ dimensions presented acceptable values and ranged between 0.20 and 0.80 . The dimension Reflection showed lower difficulty values, especially for item 15 ("I am convinced that my illness has meaning") that presented a difficulty index equal to the lowest acceptable threshold (0.20). However, this item was not

Table 3. Mean values and reliability analysis of the SpREUK subscales.

\begin{tabular}{|c|c|c|c|c|}
\hline & Mean \pm SD & $\begin{array}{l}\text { Item Difficulty } \\
\text { Index (DIF) }\end{array}$ & $\begin{array}{l}\text { Corrected item, scale } \\
\text { correlation }\end{array}$ & $\begin{array}{l}a \text { if item } \\
\text { deleted }\end{array}$ \\
\hline Search $(a=0.93)$ & $10.84 \pm 6.00$ & 0.43 & & \\
\hline 1. access to spirituality & $1.67 \pm 1.23$ & 0.33 & $0 . \overline{81}$ & $0 . \overline{91}$ \\
\hline 2. positive influence on illness & $2.17 \pm 1.45$ & 0.43 & 0.82 & 0.91 \\
\hline 3. spiritual person & $2.95 \pm 1.22$ & 0.59 & 0.82 & 0.91 \\
\hline 4. spiritual/religious insight & $2.32 \pm 1.49$ & 0.46 & 0.83 & 0.91 \\
\hline $\begin{array}{l}\text { 5. renewed interest in spiritual/ } \\
\text { religious questions }\end{array}$ & $1.73 \pm 1.42$ & 0.35 & 0.78 & 0.92 \\
\hline Trust $(a=0.81)$ & $12.72 \pm 4.49$ & 0.51 & & \\
\hline 6. trust in higher power & $2.48 \pm 1.50$ & 0.50 & 0.74 & 0.73 \\
\hline 7. religious person & $3.44 \pm 0.67$ & 0.69 & 0.59 & 0.80 \\
\hline 8. spiritual guidance in my life & $2.92 \pm 1.15$ & 0.58 & 0.81 & 0.71 \\
\hline 9. death is not an end & $2.44 \pm 1.20$ & 0.49 & 0.38 & 0.84 \\
\hline $\begin{array}{l}\text { 10. connected with a "higher } \\
\text { source" }\end{array}$ & $1.44 \pm 1.27$ & 0.29 & 0.62 & 0.77 \\
\hline Reflection $(\alpha=0.90)$ & $7.05 \pm 4.99$ & 0.28 & & \\
\hline 11. get no know myself better & $1.68 \pm 1.33$ & 0.34 & 0.78 & 0.87 \\
\hline $\begin{array}{l}\text { 12. reflect on what is essential in } \\
\text { life }\end{array}$ & $1.93 \pm 1.38$ & 0.39 & 0.81 & 0.86 \\
\hline 13. illness as a hint to change life & $1.28 \pm 1.115$ & 0.26 & 0.78 & 0.87 \\
\hline $\begin{array}{l}\text { 14. illness as a change for } \\
\text { development }\end{array}$ & $1.18 \pm 1.05$ & 0.24 & 0.81 & 0.86 \\
\hline 15. illness has meaning & $0.98 \pm 0.97$ & 0.20 & 0.59 & 0.91 \\
\hline
\end{tabular}

Alpha Total Scale: 0.95 
excluded in order to preserve the original SpREUK form and, therefore, allowing the comparison of the Portuguese version with other versions of the instrument.

\section{External validity evidence}

SpREUK scales were strongly correlated $(r>0.70)$. Analyses with external measures found negative, weak correlations between the patients' quality of life (QoL-AD) and Search $(r=-0.23, p=.009)$, Trust $(r=-0.24, p=.006)$ and Reflection ( $r=-0.22, p=.013)$ scales, as well as between mindfulness (CAMSR) and Search $(r=-0.20, p=.023)$, Trust $(r=-0.23, p=.010)$ and Reflection $(r=-0.24, p=.006)$ dimensions. Overall, the results indicate that patients with a lower quality of life and lower use of mindfulness reported a greater use of spirituality.

\section{Impact of patients' sociodemographic and clinical variables}

The impact of specific sample demographic (gender, age and education) and clinical (duration of the memory problems) characteristics on the SpREUK dimensions was analyzed (Table 4), revealing statistical significant differences for all variables. Female patients reported higher scores for all SpREUK scales. Regarding age, differences were found in one scale, showing that older patients reported higher levels of Trust. As expected, patients with no education or primary education only reported higher scores in all scales compared to those with a high school education. No differences were found between patients with no education compared with those with primary education. Finally, a longer duration of memory problems was associated with spirituality, i.e., more use of Search, Trust and Reflection (Table 4).

Table 4. Comparisons (mean \pm standard deviation) and correlations $(r)$ between SpREUK scales and patients' characteristics $(\mathrm{N}=128)$.

\begin{tabular}{llccc}
\hline & & Search & Trust & Reflection \\
\hline Patients & Women & $12.36 \pm 5.50$ & $13.74 \pm 3.86$ & $8.24 \pm 4.75$ \\
Gender & Men & $7.95 \pm 5.89$ & $10.77 \pm 4.99$ & $4.80 \pm 4.68$ \\
& $p$ & $<0.001$ & 0.001 & $<0.001$ \\
Age & $r$ & 0.136 & 0.179 & 0.052 \\
& $p$ & 0.126 & 0.043 & 0.562 \\
Education level & No education & $11.80 \pm 5.92$ & $13.36 \pm 4.51$ & $8.88 \pm 5.16$ \\
& Primary & $11.56 \pm 5.57$ & $13.12 \pm 8.69$ & $7.07 \pm 4.83$ \\
& Secondary & $4.08 \pm 5.01$ & $8.69 \pm 3.95$ & $3.46 \pm 4.01$ \\
Memory problems duration & $p$ & $<0.001$ & 0.002 & 0.006 \\
& $r$ & 0.264 & 0.217 & 0.208 \\
& $p$ & 0.003 & 0.014 & 0.018 \\
\hline
\end{tabular}




\section{Discussion}

Originally developed in the German context, the SpREUK is a multidimensional instrument designed to be used by patients with chronic diseases living in secular cultures, thus constituting an inclusive measure by avoiding religious terms that would limit the questionnaire's administration to specific spiritual-religious (S/R) beliefs and practices (Büssing, 2010; Büssing et al., 2005). Following the previous SpREUK validation studies in the European context with Arabic, Hebrew and Catholic populations, we intended to gather validation evidence within the western European culture, predominantly Catholic. The purpose of this study was to validate the Portuguese version of SpREUK-15 using a sample of patients with Alzheimer disease. As expected, the Portuguese sample consisted of 96.1\% Catholics.

Confirmatory factor analysis confirmed the primary structure of SpREUK15, confirming the original three scales: Search, Trust and Reflection. However, the model showed error correlations between items 8 and 9 (Trust) and between items 13 and 14 (Reflection) that were included in the model since both addressed common topics. In fact, issues as trust in a spiritual guidance (item 8) and conviction that dead is not the end (item 9) imply beliefs of a higher power and purpose, referring to transcendental dimensions. Also, items 13 and 14 both mention events of life as opportunities for change.

Reliability analyses revealed that all scales from the Portuguese SpREUK had good internal consistency (Search $=0.93$, Trust $=0.89$ and Reflection $=$ 0.90 ), with alphas close to the ones found in the original German version (Büssing, 2010; Search $=0.91$, Trust $=0.91$ and Reflection $=0.86$ ) and Polish (Büssing et al., 2016; Search $=0.91$, Trust $=0.75$ and Reflection $=0.75$ ) studies.

The Trust dimension was of higher relevance, while the Reflection dimension showed the lowest relevance (Search: $10.84 \pm 6.00$; Trust: $12.72 \pm 4.49$; Reflection: $7.05 \pm 4.99$ ). Results from the Polish study also found higher mean scores for the Trust dimension, in contrast with the German version that presented higher results for the Reflection scale. However, while in the Polish study, individuals were all Catholics, as the great majority of the Portuguese sample, the Germans sample included Catholics and individuals from other religions or without religion. In fact, former East Germany is the only European country of Europe in which $51 \%$ of the population reported being atheist (Casanova, 2009). In Portugal, religiosity is marked by a high trust in the Catholic Church as an institution (Mendonça, Teixeira, \& Palma, 2015). Compared with the German and Polish versions, in this Portuguese sample, patients scored lower in all dimensions, especially in the Reflection dimension, probably due to the clinical characteristic of the sample. In fact, 
in this study, patients were all in an early stage of $\mathrm{AD}$, so it is expected that the use of spirituality was not as high as in patients with advanced $A D$ (Fitchett et al., 2004). Future studies should explore further this hypothesis in patients with an advanced stage of AD. In addition, the Reflection scale implies the need to reflect on the need to seek something or someone that is transcendental (i.e. God, a higher power, spirit, energy), in order to deal with the demands imposed by the disease, emphasizing the role of $S / R$ as a coping strategy. However, this result may have to do with the fact that in this sample, patients were in an early stage of $\mathrm{AD}$ and did not feel great impairment on their quality of life and, as a result, may not feel the need to seek help or reflect on deeper values.

There is also a consistent evidence of a positive association between S/R and quality of life (Counted et al., 2018; Koenig, 2012; Lucchetti et al., 2011; Tan, Wutthilert, \& O'Connor, 2013; Vonarx \& Hyppolite, 2013). However, this finding has been reported in studies with samples that include patients with chronic diseases, such as cancer or HIV (Garssen, Uwland-Sikkema, \& Visser, 2015; Kendrick, 2017) and not in patients, who although diagnosed with a chronic disease, are at an early stage where symptoms are not overwhelming, as in this case.

Regarding the patients' characteristics, results showed that female patients reported significantly higher scores in all SpREUK subscales. Most current research indicates that women are more religious than men. However, this result may also be related to the woman's emphasis on the emotional and relational connection (Chaplin, 2015) and the fact that the sample included many more women. If the emphasis was in action and community involvement, men would possibly score as high as women. Therefore, the result showing women being more spiritual than men may simply represent a difference in how men and women express their spirituality (Rich, 2012). Future studies should pursue this hypothesis.

With respect to age, older participants presented higher levels of spirituality in terms of Trust. This result is consensual with the literature as the elderly are more likely to report a higher level of S/R (Travado et al., 2010; Zimmer et al., 2016), which may be due to the stage of the life cycle in which they are. Studies suggest that important spiritual needs emerge more in the later life cycle of aging being related to the need for meaning and purpose, love and relatedness, forgiveness and spiritual integration (Staude, 2005; Steinhauser et al., 2008). As expected, patients with no education or only primary education reported higher scores on all scales compared to those with a higher education level and no differences were found between the no eduaction and primary education groups. This result is in accordance with other studies that showed an association between lower education and more $S / R$ beliefs (Aukst-Margetic, 
Jakovljevic, Margetic, Biscan, \& Samija, 2005; Meraviglia, 2006; Travado et al., 2010).

Finally, a longer duration of memory problems was associated with more use of Search, Trust and Reflection. As previously discussed, when patients begin to feel and perceive greater health impairments, they resort more to S/ $\mathrm{R}$ as a coping strategy asking for the intercession of a higher power (Fitchett et al., 2004).

\section{Limitations}

This study has some limitations that need to be acknowledged such as the religion of the patients that was predominantly catholic, the predominance of the female gender in the sample and the low education level of patients. Future studies with the SpREUK should include bigger and more educated samples as well as patients with advanced AD.

\section{Conclusion and clinical implications}

The results showed that SpREUK has appropriate psychometric properties representing an important resource to assess spirituality in AD Portuguese patients.

The instrument may, therefore be helpful for health professionals working with $\mathrm{AD}$ patients, regardless of their religion, with the purpose of improving patients' quality of life. This study showed that patients with initial AD are more likely to resort to spirituality when their quality of life is low. The results also showed that a longer duration of memory problems was associated with spirituality. Thus, interventions with patients with initial AD should monitor patients from disease onset and focus on the development of mindfulness practices in order to boost the consciousness of the disease and promote the use of spirituality as a coping strategy, especially in men and in the elderly.

\section{Conflicts of interest}

The authors report no conflict of interests.

\section{ORCID}

M. G. Pereira (1) http://orcid.org/0000-0001-7987-2562

S. Pedras (1) http://orcid.org/0000-0001-5771-562X 


\section{References}

Adegbola, M. (2011). Spirituality, self-efficacy, and quality of life among adults with sickle cell disease. Southern Online Journal of Nursing Research, 11, 1-15.

Ali, J., Marhemat, F., Sara, J., \& Hamid, H. (2015). The relationship between spiritual well-being and quality of life among elderly people. Holistic Nursing Practice, 29, 128-135. doi:10.1097/HNP.0000000000000081

Alzheimer Portugal. (2013). Prevalência da Doença de Alzheimer [Prevalence of Alzheimer Disease]. Retrieved from http://alzheimerportugal.org/pt/alzheimer-portugal

Alzheimer's Disease International. (2009). World Alzheimer Report 2. Retrieved from https:// www.alz.co.uk/research/files/WorldAlzheimerReport.pdf

Alzheimer's Disease International. (2015). World Alzheimer report. Retrieved from https:// www.alz.co.uk/research/WorldAlzheimerReport2015.pdf

American Psychiatric Association. (2013). Diagnostic and statistical manual of mental disorders (5th ed.). Washington, DC: Author.

Aukst-Margetic, B., Jakovljevic, M., Margetic, B., Biscan, M., \& Samija, M. (2005). Religiosity, depression and pain in patients with breast cancer. General Hospital Psychiatry, 27, 250-255. doi:10.1016/j.genhosppsych.2005.04.004

Bárrios, H., Verdelho, A., Narciso, S., Gonçalves-Pereira, M., Logsdon, R., \& Mendonça, A. (2013). Quality of life in patients with cognitive impairment: Validation of the quality of life-Alzheimer's disease scale in Portugal. International Psychogeriatrics, 25, 1085-1096. doi:10.1017/S1041610213000379

Black, B. S., Johnston, D., Morrison, A., Rabins, P. V., Lyketsos, C. G., \& Samus, Q. M. (2012). Quality of life of community-residing persons with dementia based on self-rated and caregiver-rated measures. Quality Life Research, 21, 1379-1389. doi:10.1007/s11136-0110044-z

Büssing, A. (2010). Spirituality as a resource to rely on in chronic illness: The SpREUK questionnaire. Religions, 1, 9-17. doi:10.3390/rel1010009

Büssing, A., Abu-Hassan, W. M., Matthiessen, P. F., \& Ostermann, T. (2007). Spirituality, religiosity and dealing with illness in Arabic and German patients. Saudi Medical Journal, 28, 22-31. doi:10.1111/j.2042-7166.2006.tb04728.x

Büssing, A., Franczak, K., \& Surzykiewicz, J. (2016). Spiritual and religious attitudes in dealing with illness in Polish patients with chronic diseases: validation of the polish version of the SpREUK Questionnaire. Journal of Religion and Health, 55, 67-84. doi:10.1007/ s10943-014-9967-3

Büssing, A., Ostermann, T., \& Koenig, H. G. (2007). Relevance of religion and spirituality in German patients with chronic diseases. International Journal of Psychiatry in Medicine, 37, 39-57. doi:10.2190/60W7-1661-2623-6042

Büssing, A., Ostermann, T., \& Matthiessen, P. F. (2005). Role of religion and spirituality in medical patients: Confirmatory results with the SpREUK questionnaire. Health and Quality of Life Outcomes, 3, 1-10. doi:10.1186/1477-7525-3-10

Carmody, J., Reed, G., Kristeller, J., \& Merriam, P. (2008). Mindfulness, spirituality, and health-related symptoms. Journal of Psychosomatic Research, 64, 393-403. doi:10.1016/j. jpsychores.2007.06.015

Casanova, J. (2009). The religious situation in Europe. In H. Joas \& K. Wiegandt (Eds.), Secularization and the world religions (pp. 206-227). United Kingdom: Liverpool University Press.

Chaplin, T. M. (2015). Gender and emotion expression: A developmental contextual perspective. Emotion Review, 7(1), 14-21. doi:10.1177/1754073914544408 
Chen, Y. H., Lin, L. C., Chuang, L. L., \& Chen, M. L. (2017). The relationship of physiopsychosocial factors and spiritual well-being in elderly residents: Implications for evidence-based practice. Worldviews Evidence Based Nursing, 14, 484-491. doi:10.1111/ wvn. 12243

Clayton-Jones, D., \& Haglund, K. (2016). The role of spirituality and religiosity in persons living with sickle cell disease: A review of the literature. Journal of Holistic Nursing, 34, 351-360. doi:10.1177/0898010115619055

Conde-Sala, J. L., Garre-Olmo, J., Turró-Garriga, O., López-Souza, S., \& Vilalta-Franch, J. (2009). Factors related to perceived quality of life in patients with Alzheimer's disease: The patient's perception compared with that of caregivers. International Journal of Geriatric Psychiatry, 24, 585-594. doi:10.1002/gps.2161

Counted, V., Possamai, A., \& Meade, T. (2018). Relational spirituality and quality of life 2007 to 2017: An integrative research review. Health and Quality of Life Outcomes, 16, 1-18. doi:10.1186/s12955-018-0895-x

Dalby, P., Sperlinger, D. J., \& Boddington, S. (2011). The lived experience of spirituality and dementia in older people living with mild to moderate dementia. Dementia, 11, 75-94. doi:10.1177/1471301211416608

Davison, S. N., \& Jhangri, G. S. (2013). The relationship between spirituality, psychosocial adjustment to illness, and health-related quality of life in patients with advanced chronic kidney disease. Journal of Pain and Symptom Management, 45, 179.178. doi:10.1016/j. jpainsymman.2012.02.019

Dourado, M., Laks, J., Leibing, A., \& Engelhardt, E. (2006). Consciência da doença na demência [Disease awareness in dementia]. Revista de Psiquiatria Clínica, 33, 313-321. doi:10.1590/S0101-60832006000600004

Feldman, G., Hayes, A., Kumar, S., Greeson, J., \& Laurenceau, J. (2007). Mindfulness and emotion regulation: The development and initial validation of the Cognitive and Affective Mindfulness Scale-Revised (CAMS-R). Journal of Psychopathology and Behavioral Assessment, 29, 177-190. doi:10.1007/s10862-006-9035-8

Fitchett, G., Murphy, P. E., Kim, J., Gibbons, J. L., Cameron, J. R., \& Davis, J. A. (2004). Religious struggle: Prevalence, correlates and mental health risks in diabetic, congestive heart failure, and oncology patients. The International Journal of Psychiatry in Medicine, 34 (2), 179-196. doi:10.2190/UCJ9-DP4M-9C0X-835M

Garssen, B., Uwland-Sikkema, N. F., \& Visser, A. (2015). How spirituality helps cancer patients with the adjustment to their disease. Journal of Religion and Health, 54, 1249-1265. doi:10.1007/s10943-014-9864-9

Greeson, J. M., Smoski, M. J., Suarez, E. C., Brantley, J. G., Ekblad, A. G., Lynch, T. R., \& Wolever, R. Q. (2015). Decreased symptoms of depression after mindfulness-based stress reduction: Potential moderating effects of religiosity, spirituality, trait mindfulness, sex, and age. Journal of Alternative and Complementary Medicine, 21, 166-174. doi:10.1089/ acm.2014.0285

Hair, F., Anderson, R., Tatham, R., \& Black, W. (1995). Multivariate data analysis: With readings. Englewood Cliffs, NJ: Prentice-Hall.

Hermida, R. (2015). The problem of allowing correlated errors in structural equation modeling: Concerns and considerations. Computational Methods in Social Sciences, 3 (1), 5-17.

Hu, L. T., \& Bentler, P. M. (1995). Evaluating model fit. In R. H. Hoyle (Ed.), Structural equation modeling: Concepts, issues, and applications (pp. 76-99). Thousands Oaks, CA: Sage.

Katsuno, T. (2003). Personal spirituality of persons with early-stage dementia: Is it related to perceived quality of life? Dementia, 2, 315-335. doi:10.1177/14713012030023003 
Kendrick, M. H. (2017). Are religion and spirituality barriers or facilitators to treatment for HIV: A systematic review of the literature. AIDS Care, 29, 1-13. doi:10.1080/ 09540121.2016 .1201196

Koenig, G. H. (2012). Religion, spirituality, and health: The research and clinical implications. International Scholarly Research Network ISRN Psychiatry, Article ID, 278730, 1-33. doi:10.5402/2012/278730

Logsdon, R. G., Gibbons, L. E., McCurry, S. M., \& Teri, L. (2002). Assessing quality of life in older adults with cognitive impairment. Psychosomatic Medicine, 64, 510-519. doi:10.1097/ 00006842-200205000-00016

Lucchetti, G., Lucchetti, A. G., Badan-Neto, A. M., Peres, P. T., Peres, M. F., MoreiraAlmeida, A., ... Koening, H. G. (2011). Religiousness affects mental health, pain and quality of life in older people in an outpatient rehabilitation setting. Journal of Rehabilitation Medicine, 43, 316-322. doi:10.2340/16501977-0784

McGee, J., Carlson, H., \& Myers, D. (2013). Development of the dimensions of living with memory loss interview. Alzheimer's \& Dementia: the Journal of the Alzheimer'S Association, 9, 644-645. doi:10.1016/j.jalz.2013.05.1312

Mendonça, J. T., Teixeira, A., \& Palma, A. (2015). Religion and culture in the process of global change: Portuguese perspectives. In G. F. McLean (Ed.), Cultural heritage and contemporary change, series VIII, Christian philosophical studies (Vol. 19, pp. 1-195). Washington, DC: The Council for Research in Values and Philosophy.

Meraviglia, M. (2006). Effects of spirituality in breast cancer survivors. Oncology Nursing Forum, 33, E1-7. doi:10.1188/06.ONF.E1-E7

Orhan, G., Orhan, I., Subutay-Oztekin, N., Ak, F., \& Sener, B. (2009). Contemporary anticholinesterase pharmaceuticals of natural origin and their synthetic analogues for the treatment of Alzheimer's disease. Recent Patents on CNS Drug Discovery, 4, 43-51. doi:10.2174/157488909787002582

Pereira, M. G., Rego, D., \& Lima, S. (2015). Adaptation of the Cognitive and Affective Mindfulness Scale-Revised in Alzheimer's Disease: Patients, Informal and Formal caregivers. In Family Health \& Illness Research Group [http://www.saudefamiliaredoenca.pt/]. School of Psychology.University of Minho, Portugal.

Powell, L. H., Shahabi, L., \& Thoresen, C. E. (2003). Religion and spirituality. Linkage to physical health. The American Psychologist, 58, 36-52. doi:10.1037/0003-066X.58.1.36

Rich, A., II. (2012). Gender and spirituality are women really more spiritual? (Senior Honors' thesis). Retrieved from https://digitalcommons.liberty.edu/honors/281/

Seeman, T. E., Dubin, L. F., \& Seemann, M. (2003). Religiosity/spirituality and health. A critical review of the evidence for biological pathways. American Psychologist, 58, 53-63. doi:10.1037/0003-066X.58.1.53

Sloan, R., \& Bagiella, E. (2002). Claims about religious involvement and health outcomes. Annals of Behavioral Medicine, 24, 14-21. doi:10.1207/S15324796ABM2401_03

Staude, J. R. (2005). Autobiography as a spiritual practice. Journal of Gerontological Social Work, 45, 249-269. doi:10.1300/J083v45n03_01

Steinhauser, K. E., Alexander, S. C., Byock, I. R., George, L. K., Olsen, M. K., \& Tulsky, J. A. (2008). Do preparation and life completion discussions improve functioning and quality of life in seriously ill patients? Pilot randomized control trial. Journal of Palliative Medicine, 11, 1234-1240. doi:10.1089/jpm.2008.0078

Sullivan, S. C., \& Beard, R. L. (2014). Faith and forgetfulness: The role of spiritual identity in preservation of self with Alzheimer's. 26, 65-91. doi:10.1080/15528030.2013.811462

Tan, H., Wutthilert, C., \& O'Connor, M. (2013). Spirituality and quality of life in older people with chronic illness in Thailand. Progress in Palliative Care, 19, 177-184. doi:10.1179/ 1743291X11Y.0000000013 
Travado, L., Grassi, L., Gil, F., Martins, C., Ventura, C., \& Bairradas, J. (2010). Do spirituality and faith make a difference? Report from the Southern European psycho-oncology study group. Palliative and Supportive Care, 8, 405-413. doi:10.1017/S147895151000026X

Ullman, J. B. (2001). Structural equation modeling. In B. G. Tabachnick \& L. S. Fidell (Eds.), Using multivariate statistics (4th ed., pp. 653-771). Boston, MA: Pearson.

Vonarx, N., \& Hyppolite, S. R. (2013). Religion, spirituality, and cancer: The question of individual empowerment. Integrative Cancer Therapies, 12, 69-80. doi:10.1177/ 1534735411433835

Woods, R. T., Nelis, S. M., Martyr, A., Robert, J., Whitaker, C. J., Markova, I., ... Clare, L. (2014). What contributes to a good quality of life in early dementia? Awareness and the QoL-AD: A crossectional study. Health and Quality of Life Outcomes, 12, 1-11. doi:10.1186/1477-7525-12-94

Zimmer, Z., Jagger, C., Chiu, C. T., Ofstedal, M. B., Rojo, F., \& Saito, Y. (2016). Spirituality, religiosity, aging and health in global perspective: A review. SSM - Population Health, 2, 373-381. doi:10.1016/j.ssmph.2016.04.009

Zini, A., Büssing, A., \& Sgan-Cohen, H. D. (2010). Validity and reliability of the hebrew version of the SpREUK questionnaire for religiosity, spirituality and health: An application for oral diseases. Religions, 1, 86-104. doi:10.3390/rell010086 